\title{
Classical appetitive conditioning in the pigeon: Partial reinforcement'
}

ROBERT M. SLIVKA AND M. E, BITTERMAN

BRYN MAWR COLLEGE

Light and food were paired for two groups of pigeons, one consistently and the other partially reinforced in an equatedreinforcements design. The over-all level of response to light (stabilimetrically measured) was the same in the two groups, both in acquisition and in extinction, although a significant Groups by Trials interaction appeated in extinction. The relation of these results to those of other experiments on partial reinforcement in classical conditioning is noted, and their implication for the problem of adventitious reinforcement is considered.

In a recent experiment on classical conditioning in the pigeon, a CS-US interval of $10 \mathrm{sec}$. was found to produce better conditioning than an interval of 1 sec. (Longo, Klempay, \& Bitterman, 1964). The technique employed was to pair a CS with food and to measure the general activity which the $\mathrm{CS}$ came in consequence to evoke. The unusual outcome of the experiment suggested that adventitious reinforcement of response to the CS by the appetitive US might play an important role in the situation, the longer CS-US interval being assumed to provide greater opportunity for the operation of such a process. The results of the present experiment, in which the properties of the technique were explored further, bear on the validity of this interpretation. Method

Six Ss are trained simultaneously in ventilated picnic chests. Each chest is divided into two compartments by a black Plexiglas partition. S's compartment is about $11 \mathrm{in}$. long, $11 \mathrm{in}$. wide, and $13 \mathrm{in}$. high. Its floor is a spring-mounted platform linked by a light rod to a phonograph cartridge fixed to the floor of the chest on the other side of the partition. To $\mathrm{S}$, the partition displays only a feeding tray of white Plexiglas which can be illuminated with blue or white light, and into which about $2.5 \mathrm{gm}$ of mixed grain can be discharged from a hopper by the action of a solenoid; hopper and solenoid, colored lamps, and associated wiring are mounted behind the partition. To measure S's activity during the CS-US interval or during control periods of no stimulation, the amplified output of the phonograph cartridgeis used to drive a relay which operates one pen of an eventrecorder. The pen rises at the start of the period in which activity is to be measured, falls momentarily as each unit of activity is generated, and then returns to the rest position at the end of the period. All of the events of the experiment are programmed automatically.

The Ss were 24 experimentally naive White Carneaux cocks reduced to $85 \%$ of their free-feeding weights on a 24-hr. schedule and pretrained to take food readily from the blue-lighted trays in the conditioning chambers. In the experiment proper, the animals were trained in daily 15-'trial' sessions, with a mean intertrial interval of about $6 \mathrm{~min}$. and a range of $2-10 \mathrm{~min}$. On the first nine days of acquisition, all Ss were constantly reinforced; there were five reinforced conditioning trials and 10 interspersed activity 'trials.' The CS was a change in the color of the tray-light from dim blue to bright white, which was followed $20 \mathrm{sec}$. later by the presentation of food (US), whereupon the tray light became blue once more. The 20-sec. activity trials, on which neither the CS nor the US was presented, were used to obtain measures of basal activity.

On the basis of their performance in the first nine days of acquisition, the animals were divided into two equated groups of $12 \mathrm{Ss}$ each, Consistent and Partial. The training of the Consistent Group continued as before on days 10-25, but for the Partial Group five unreinforced presentations of the CS were substituted for five of the activity trials. To begin with, the reinforced and unreinforced trials of the Partial Group followed each other in Gellermann orders (with a maximum of only three unreinforced trials in succession), but as training continued longer runs of unreinforced trials were introduced $(4,5,8,10$, and 10 on days 13,15 , $17-18,20-21$, and 23-24, respectively). Both groups were extinguished on days 26-31, with five unreinforced presentations of the CS and 10 activity trials on each day.

Results

In Fig. 1, the course of acquisition and extinction in the two groups is plotted in terms of mean magnitude of response to the CS on each day, with mean magnitude of response on activity trials plotted for purposes

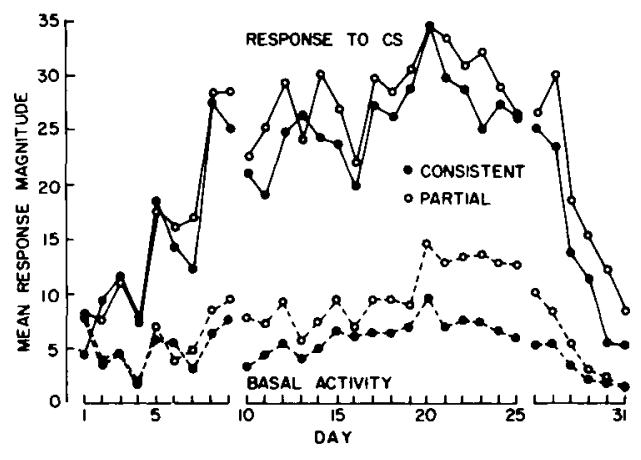

Fig. 1. Mean magnitude of response to the CS and mean basal activity in acquisition and extinction sessions. 
of comparison. The curves for the second phase of the experiment (days 10-25) in which the two groups were treated differently are based on identical trials - the reinforced conditioning trials and the activity trials for the Partial Group. A Lindquist Type I analysis of response to the $C S$ on acqusition days 10-25 yielded a significant Days effect $(F=5.06$, $\mathrm{df}=15 / 330, \mathrm{p}<.01)$, but neither a significant Groups effect $(F<1)$ nor a significant interaction $(F<1)$. A Lindquist Type VI analysis of response to the CS in extinction also yielded a significant Days effect $(F=32.17$, $\mathrm{df}=5 / 110, \mathrm{p}<.01$ ), as well as a significant effect of Trials Within Days $(F=4.89, \mathrm{df}=4 / 88, \mathrm{p}<.01)$. The Groups effect was insignificant $(F<1)$, but evidence of greater resistance to extinction following partial reinforcement appeared in the form of a significant Groups by Trials interaction $(F=5.25, \mathrm{df}=4 / 88, \mathrm{p}<.01$ ) The nature of the interaction is shown by Fig. 2 in which mean magnitude of response to the CS is plotted over trials. On the chance that magnitude of response might be an insufficiently sensitive measure, magnitudes of response were converted to probabilities of response; a significant Groups effect failed to appear in any of four separate analyses with response defined as $5,10,20$, and 30 units of activity, respectively (F-values ranging from less-than-1 to 1.49).

\section{Discussion}

The partial reinforcement effect has not appeared as dependably in classical conditioning situations as it has in instrumental situations. Greater over-all level of response in extinction after partial as compared with consistent reinforcement has been found in some experiments-with the African mouthbreeder by Gonzalez, Eskin, \& Bitterman (1963) and with the earthworm by Wyers, Peeke, \& Herz (1964)-but not in a substantial number of others. The results of a

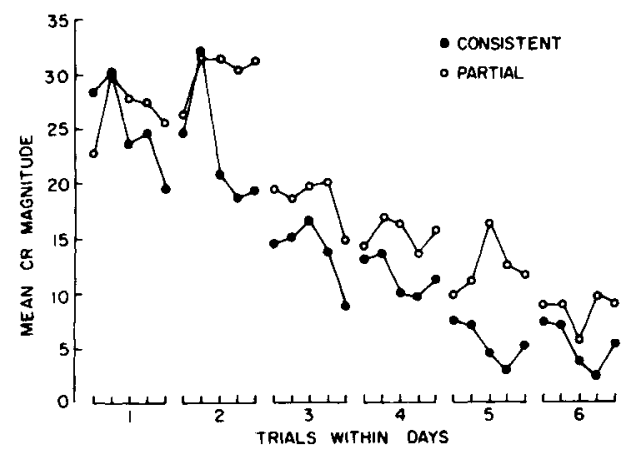

Fig. 2. Mean magnitude of response to the $\mathrm{CS}$ on individual extinction trials. long series of experiments with the goldfish have been negative for the most part, although special schedules have in some cases given evidence of greater resistance after partial reinforcement which takes the form, not of a Groups effect, but of a Groups by Days or a Groups by Trials interaction (Berger, Yarczower, \& Bitterman, 1965). An experiment with the rabbit has given entirely negative results (Thomas \& Wagner, 1964), and two experiments with the dog have produced nothing but interactive evidence of the PRE (Fitzgerald, 1963; Wagner, Siegel, Thomas, \& Ellison, 1964)。

Whatever the reasons for these discrepancies, the present results closely resemble those of analogous classical conditioning experiments with the goldfish (Berger, Yarczower, \& Bitterman, 1965) in which a CS was paired with shock and the general activity that it came in consequence to evoke was measured. Since shock cannot be thought of as adventitious reward for response to the CS, and since it is easy with a real response-reward contingency to produce the PRE in the pigeon (Roberts, Bullock, \& Bitterman, 1963), we may doubt that adventitious reward plays a substantial role in the situation of the present experiment. Perhaps, then, an explanation of the unique results for CS-US interval which have been obtained in the same situation should be sought elsewhere.

\section{References}

Berger, B. D., Yarczower, M., \& Bitterman, M. E. Eff ect of partial reinforcement on the extinction of a classically conditioned response in the goldfish. J. comp. physiol. Psychol., 1965,59, 399-405.

Fitzgerald, R. D. Effects of partial reinforcement with acid on the classically conditioned saiivary response in dogs. J. comp. physiol. Psychol., 1963, 56, 1056-1060.

Gonzalez, R. C., Eskin, R. M., \& Bitterman, M. E. Further experiments on partial reinforcement in the fish. Amer. J. Psychol., 1963, 76, 366-375.

Longo, N., Klempay, S., \& Bitterman, M. E. Classical appetitive conditioning in the pigeon. Psychon, Sci., 1964, 1, 19-20.

Roberts, W. A., Bullock, D. H., \& Bitterman, M. E. Resistance to extinction in the pigeon after partially reinforced instrumental training under discrete-trials conditions. Amer. J. Psychol., $1963,76,353-365$.

Thomas, E., \& Wagner, A. R. Partial reinforcement of the classically conditioned eyelid response in the rabbit. J. comp. physiol. Psychol., 1964, 58, 157-158.

Wagner, A. R., Siegel, S., Thomas, E., \& Ellison, G. D. Reinforcement history and the extinction of a conditioned salivary response. J. comp. physiol. Psychol., 1964, 58, 354-358.

Wyers, E. J., Peeke, H. V. A., \& Herz, M. J. Partial reinforcement and resistance to extinction in the earthworm. J. comp. physiol. Psychol., 1964, 57, 113-116.

\section{Note}

1. This work was supported by Contract Nonr 2829(01) with the Office of Naval Research. 